\title{
Hook Plate for Volar Rim Fractures of the Distal Radius: Review of the First 23 Cases and Focus on Dorsal Radiocarpal Dislocation
}

\author{
Marco Biondi, MD ${ }^{1}$ Marco Keller, MD $\quad$ Letizia Merenghi, MD ${ }^{3} \quad$ Markus Gabl, MD ${ }^{2} \quad$ Giulio Lauri, MD ${ }^{1}$ \\ ${ }^{1}$ Hand Surgery Unit, Azienda Ospedaliero Universitaria Careggi, \\ Florence, Italy \\ 2 Division of Hand Surgery, Department of Trauma Surgery, Medical \\ University Innsbruck, Innsbruck, Austria

\begin{abstract}
Address for correspondence Marco Biondi, MD, Hand Surgery Unit, Azienda Ospedaliero Universitaria Careggi, Largo Palagi 1, Florence, Italy (e-mail: marcobiondi@ymail.com).
\end{abstract}

${ }^{3}$ Orthopedic Clinic, Ospedale Maggiore, Parma, Italy

J Wrist Surg 2019;8:93-99.

\begin{abstract}
Keywords

- volar rim

- hook plate

- radiocarpal dislocation

- distal radius fractures

- volar locking plate

Background Fragment-specific fixation of the distal radius is born to fix each articular fragment with limited surgical approach and low-profile devices. Over time, many devices with different designs and characteristics have been developed. However, many of them have showed the inability to securely fix marginal, small, and comminuted fragments as bony ligament avulsions and bony compression injuries.

Purpose The purpose of this study was to evaluate the clinical and radiological outcome of a new device born to treat marginal articular fractures of the distal radius. Patients and Methods A retrospective review was conducted on 23 patients with a mean follow-up of 21 months including postoperative clinical evaluation, grip strength, computed tomography scan, and X-ray control.

Results All fragments healed and maintained reduced until the final follow-up. The carpus was aligned with the distal radius in all patients presenting with a radiocarpal dislocation.

Conclusion The volar rim fragment is an attachment site for the short radiolunate and the volar distal radioulnar ligament. Its unstable fixation can lead to articular incongruity, volar or dorsal subluxation of the carpus, and distal radioulnar instability. The involvement of this fragment on distal radius fractures is relatively common and many studies of the literature have been focused on its treatment. The Hook Plate stabilizes distal fragments at their bone-ligament interface. In addition to bony reduction, the device permits to stabilize the capsule and ligaments, as volar bony ligament avulsions, in a picture of dorsal radiocarpal dislocation.

Level of Evidence This is a Level IV, case series.
\end{abstract}

The advent of fixed-angle locking plate osteosynthesis has significantly changed the treatment of distal radius fractures and now represents the gold standard of treatment. During the years, locking plate fixation has showed several limitations to fix and stabilize small articular fragments distal of the watershed line. Their loss of reduction can lead to an articular incongruity, loss of structural support, and may ultimately result in carpal subluxation or dislocation. ${ }^{1-3}$ Medoff $^{4}$ characterized the major fracture fragments of the articular surface of the radius as the volar rim, the dorsal ulnar corner, the dorsal wall, the free articular pieces, and the radial column. Each fragment is the result of a capsule-ligamentous avulsion, in received

April 16, 2018

accepted

June 15, 2018

published online

August 7, 2018
Copyright @ 2019 by Thieme Medical Publishers, Inc., 333 Seventh Avenue, New York, NY 10001, USA. Tel: +1(212) 584-4662.
DOI https://doi.org/

10.1055/s-0038-1667306. ISSN 2163-3916. 
which the individual ligament contributes to the fracture location by transmission of the tensile force to the rim of the articular surface. Medoff, with his work, focused on the volar rim fracture, which maintain of reduction can be particularly difficult also leading to catastrophic volar carpal subluxation or dislocation. He was also one of the first authors to develop and popularize the fragment-specific fixation, ${ }^{5}$ a different concept of fixation born to stabilize each articular fragment with a limited surgical approach and low-profile devices. Over time, many devices with different designs and characteristics have been developed according to the fragment-specific fixation. However, many of them showed the inability to securely fix and maintain reduced marginal, small, and comminuted fragments as ligament avulsions ${ }^{6}$ and bony compression injuries. This work evaluates our experience with the fragmentspecific Hook Plate (Aptus Wrist Distal Radius System 2.5, Medartis AG). The Hook Plate is a system available in two different widths: a plate with two distal hooks and two holes for proximal screws that fix the implant, and a double Hook Plate with four hooks and four holes for proximal screws insertion. The device has a low profile $(0.6 \mathrm{~mm})$ and is fixed with two (or four) $1.5 \mathrm{~mm}$ self-drilling SpeedTip screws for fast and easy insertion. Compared with other devices, the Hook Plate stabilizes the articular fragment on their bone-ligament interface and is able to fix small and comminuted fragments. It can be freely positioned along the whole edge of the articular surface of the radius staying distal to the watershed line and not precluding a proximal locking plate fixation.

\section{Materials and Methods}

The study is based on a retrospective review of 23 patients treated for an articular fracture of the distal radius. Fixation was performed with the Hook Plates of the Aptus Wrist System (Medartis AG). The study was conducted in 12 patients at the Hand Surgery Unit, Azienda Ospedaliero Universitaria Careggi (Florence, Italy) and in 11 patients at the Hand Surgery Unit of the Traumatology Department, Medical University (Innsbruck, Austria).

Twenty patients were male, three were women and their mean age was 38 years (range, 19-78). All patients presented for an articular involvement that could be classified as B3 or C3 basing on AO classification. However, as articular fragments cannot be identified using the AO classification, we applied Medoff's classification. This classification identifies five main articular distal radius fragments as the volar rim, the dorsal ulnar corner, the dorsal wall, the free articular pieces, and the radial column. The mean follow-up was 21 months (range, 16-31).

Patients were classified based on preoperative computed tomography (CT) and X-ray scans through the number of articular fragments involved in the fracture:

- Nine patients presented for a fracture of all the five fragments.

- One patient presented for a fracture of four fragments.

- Six patients presented for a fracture of three fragments.

- Five patients presented for a fracture of two fragments.

- Two patients presented for a fracture of one fragment.
The most common mechanism of injury was a motor vehicle collision. In particular, six patients presented for a dorsal distal radius comminution and dorsal radiocarpal subluxation after a fall with the wrist in flexion attempting to break with the motorcycle ("throttle lesion"). In these patients, the volar rim fracture was caused by the dislocation of the anchorage point of the short radiolunate ligament and the surgical treatment was of utmost importance to stabilize the radiocarpal joint (-Fig. $\mathbf{1}$ ).

Individual patient demographics, diagnosis, and surgical treatment are shown in - Table 1. Various combination of volar and dorsal plate fixations were used to treat these patients. Nine patients were treated with a headless cannulated compression screw on the radial styloid and a single or double Hook Plate on the volar rim. In these cases, the Hook Plate was applied with a low-profile volar approach, opening only the distal part of the pronator quadratus.

Two patients presented with a volar subluxation of the carpus for impacted lunate fossa that was fixed with one double Hook Plate (-Fig. 2). Thirteen patients required a single volar approach, of which nine of them had to be treated with a cannulated headless screw for the styloid fracture and a Hook Plate for the volar rim fracture (-Fig. 3). In four patients, the Hook Plate was added to a volar locking plate metaphyseal fixation. The remaining 10 patients required a combined volar and dorsal approach with both dorsal and volar plate fixations plus Hook Plate to stabilize the volar rim. In these patients, the dorsal plate was used to buttress the articular dorsal distal radius dislocation, while the volar locking plate was used to stabilize the radial styloid column and/or the metaphysis. All patients started an early postoperative rehabilitation 2 weeks after surgery.

Clinical assessment was performed at the last follow-up using subjective questionnaires such as visual analog scale (VAS), Patient-Related Wrist Evaluation (PRWE), and Disabilities of the Arm, Shoulder, and Hand (DASH) scores. The objective evaluation was performed measuring range of motion of the injured wrist and grip strength measured bilaterally with Jamar Dynamometer. Latest radiographs were recorded to evaluate radial inclination, volar tilt, ulnar variance, and for a presence of ulnar head instability. A postoperative CT scan was performed for 12 patients to evaluate complications such as loss of fragments reduction, loss of radiocarpal alignment, and Hook Plate failure.

\section{Results}

The mean follow-up was 21 months (range, 16-31).

The average VAS at final follow-up was 1.1 (range, 0-5). The evaluation with DASH showed a wide range score from 1.7 to 47.5 , with a mean score of 13.5 points due to different pattern and severity of the fractures. The same trend was seen in the PRWE questionnaire with an average score of 9.3 points (range, $1-17$ ).

Final average amount of wrist motion was 90 degrees (range, 40-160) of flexion-extension, 150 degrees (range, 


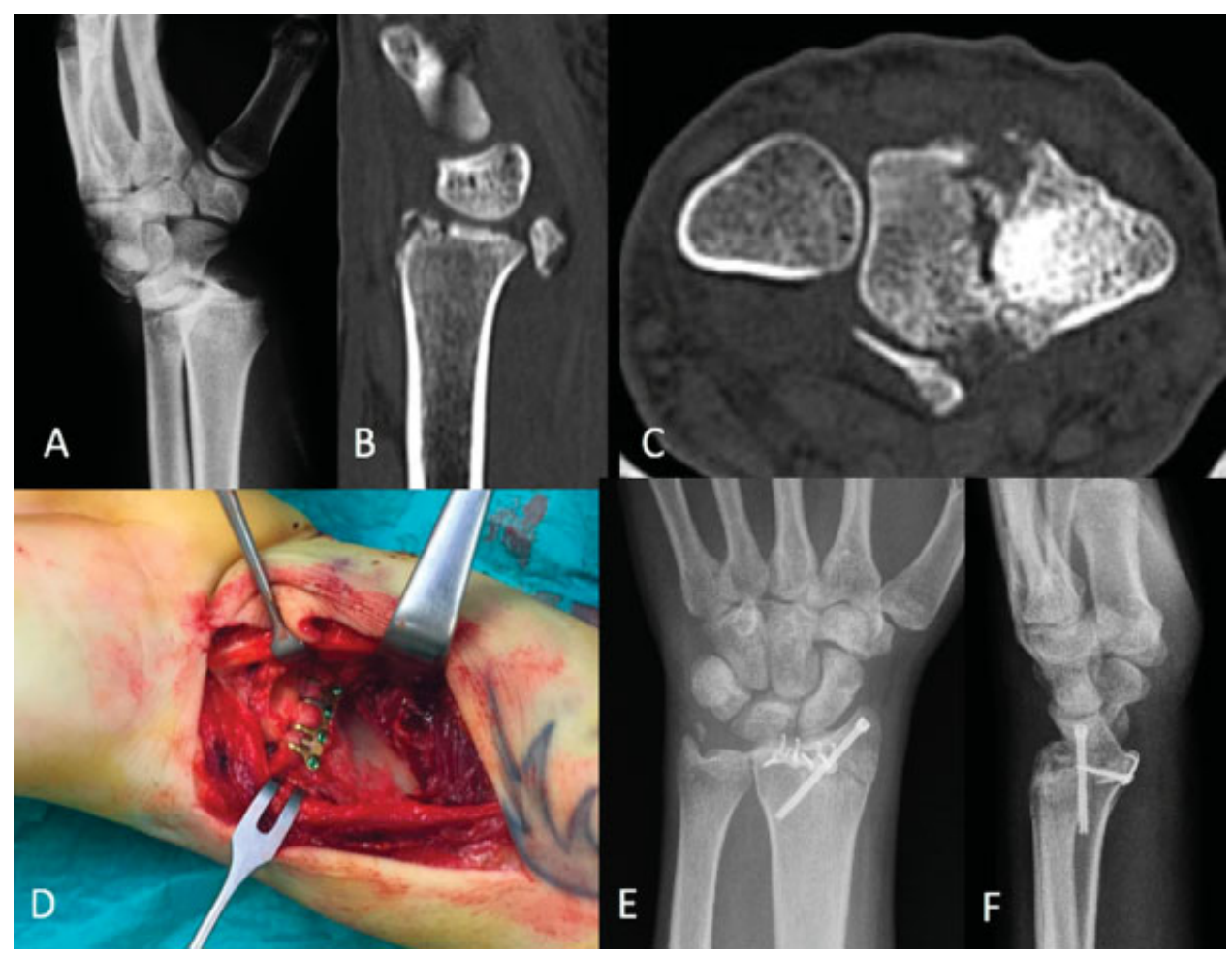

Fig. 1 (A) Dorsal distal radius comminution and dorsal radiocarpal subluxation after a fall with the wrist in flexion attempting to break with the motorcycle ("throttle lesion"). (B, C) The computed tomography was performed after reduction. In this patient, the volar rim fracture was caused by the dislocation and rotation of the anchorage point of the short radiolunate ligament and the surgical treatment was of utmost importance to stabilize the radiocarpal joint. (D) Intraoperative image and (E, F) postoperative X-ray control.

100-180) of pronation-supination, 17 degrees (range, 1035) of radial deviation, and 36 degrees (range, 10-40) of ulnar deviation. No clinical signs or symptoms of distal radioulnar instability were observed. Final grip strength averaged $40.8 \mathrm{~kg}$ (range, 20-68), representing an average of $89 \%$ of the contralateral and uninvolved grip strength.

The final average radiographic measurements were 8.5 degrees of volar tilt (range, -1.5-13.1), 19 degrees of ulnar inclination (range, 10-35), and $1 \mathrm{~mm}$ of ulnar negative variance (range, $2 \mathrm{~mm}$ of ulnar negative variance to $2 \mathrm{~mm}$ of ulnar positive variance).

Complications related to the Hook Plates, such as loss of fixation or reduction, articular prominence of the screws, reoperation, tenosynovitis, or tendon ruptures were not observed. Union was achieved in all patients, and no hardware failure was registered.

CT scan evaluation was performed on the last follow-up in 12 of the 25 patients. The exam was performed to evaluate each fragments stabilized with the Hook Plate individually. Results showed that all the fragments healed and maintained reduced until the final follow-up. The carpus was aligned with the distal radius in all the 10 patients presenting with a radiocarpal dislocation. The $\mathrm{CT}$ scan showed an interesting result in one patient with the whole reabsorption of the volar fragment stabilized with the Hook Plate at the last 13th month follow-up. However, the device did not show any signs of loosening or failure, and the carpus remained aligned with the distal radius ( - Fig. 4). This finding confirmed the ability of the Hook Plate to fix the bone-ligament interface in cases of bony ligament avulsion fractures.

\section{Discussion}

Important ligaments as radiocarpal and radioulnar ligaments attach to the distal edge of the radius. ${ }^{7}$ During a dorsal radiocarpal subluxation or dislocation, the tensile force of the radiocarpal ligaments can cause a volar avulsed articular fracture, sometimes with small bony ligament fragments that are challenging to stabilize. On the contrary, bony compression injuries can lead to an impaction of the articular surface of the radius with volar subluxation of the carpus. A rotation of these small and distal articular fragments could be easily missed with conventional radiographs, increasing the risk of late radiocarpal and radioulnar instability ${ }^{8}$ or osteoarthrosis. Conservative treatment of these fractures is not appropriate and the surgical treatment of the sequel, as corrective osteotomy or a radiocarpal fusion, can be demanding for the hand surgeon ${ }^{9,10}$ and not satisfactory for the patient.

Based on Medoff's distal radius classification, the articular surface of the radius can be fractured into five main fragments (key fragments): the volar rim, the dorsal ulnar corner, the dorsal wall, free articular pieces, and the radial column. The volar rim fragment is an attachment site for the short radiolunate and the volar distal radioulnar ligament, ${ }^{4}$ and its unstable fixation can lead to articular incongruity, volar subluxation of the carpus, ${ }^{11}$ and distal radioulnar 
96 Hook Plate for Volar Rim Fractures of the Distal Radius Marco et al.

Table 1 Patients' data

\begin{tabular}{|c|c|c|c|c|c|c|c|c|}
\hline Patient & Age & $\begin{array}{l}\text { Follow-up } \\
\text { (mo) }\end{array}$ & $\begin{array}{l}\text { Mechanism } \\
\text { of injury }\end{array}$ & $\begin{array}{l}\text { Number of } \\
\text { articular } \\
\text { fragments }\end{array}$ & $\begin{array}{l}\text { Presence of } \\
\text { radiocarpal } \\
\text { subluxation }\end{array}$ & $\begin{array}{l}\text { Surgical } \\
\text { treatment }\end{array}$ & $\begin{array}{l}\text { Fragments } \\
\text { fixed by } \\
\text { Hook Plate }\end{array}$ & $\begin{array}{l}\text { Postoperative } \\
\text { CT scan } \\
\text { follow-up }\end{array}$ \\
\hline 1 & 37 & 22 & Car accident & 2 & No & $\begin{array}{l}\text { Volar plate, } \\
\text { HooK Plate }\end{array}$ & Volar rim & Yes \\
\hline 2 & 29 & 21 & Throttle lesion & 3 & Dorsal & $\begin{array}{l}\text { Headless screw, } \\
\text { double Hook Plate }\end{array}$ & Volar rim & No \\
\hline 3 & 47 & 19 & Throttle lesion & 3 & Dorsal & $\begin{array}{l}\text { Dorsal plate, } \\
\text { headless screw, } \\
\text { double Hook Plate }\end{array}$ & Volar rim & Yes \\
\hline 4 & 22 & 20 & Fall from above & 5 & No & $\begin{array}{l}\text { Dorsal plate, } \\
\text { double Hook Plate }\end{array}$ & Volar rim & Yes \\
\hline 5 & 78 & 124 & Throttle lesion & 2 & Dorsal & $\begin{array}{l}\text { Headless screw, } \\
\text { double Hook Plate }\end{array}$ & Volar rim & Yes \\
\hline 6 & 34 & 13 & Throttle lesion & 5 & Dorsal & $\begin{array}{l}\text { Headless screw, } \\
\text { double Hook Plate }\end{array}$ & Volar rim & No \\
\hline 7 & 73 & 17 & Throttle lesion & 5 & No & $\begin{array}{l}\text { Dorsal plate, } \\
\text { headless screw, } \\
\text { Hook Plate }\end{array}$ & Volar rim & Yes \\
\hline 8 & 20 & 16 & Sport accident & 5 & No & $\begin{array}{l}\text { Volar plate, } \\
\text { Hook Plate }\end{array}$ & Volar rim & Yes \\
\hline 9 & 19 & 15 & Throttle lesion & 5 & Dorsal & $\begin{array}{l}\text { Dorsal plate, } \\
\text { double Hook Plate }\end{array}$ & Volar rim & Yes \\
\hline 10 & 25 & 23 & Throttle lesion & 5 & Dorsal & $\begin{array}{l}\text { Dorsal plate, } \\
\text { volar plate, } \\
\text { double Hook Plates }\end{array}$ & Volar rim & Yes \\
\hline 11 & 50 & 12 & Fall from stairs & 1 & Volar & $\begin{array}{l}\text { Volar plate, } \\
\text { double Hook Plates }\end{array}$ & Volar rim & Yes \\
\hline 12 & 63 & 11 & $\begin{array}{l}\text { Motorcycle } \\
\text { accident }\end{array}$ & 5 & No & $\begin{array}{l}\text { Volar plate, } \\
\text { Hook Plate }\end{array}$ & Volar rim & Yes \\
\hline 13 & 32 & 32 & Fall from ladder & 3 & No & $\begin{array}{l}\text { Volar plate, } \\
\text { Hook Plate }\end{array}$ & Volar rim & No \\
\hline 14 & 45 & 28 & $\begin{array}{l}\text { Motorcycle } \\
\text { accident }\end{array}$ & 3 & No & $\begin{array}{l}\text { Headless screw, } \\
\text { Hook Plate }\end{array}$ & Volar rim & No \\
\hline 15 & 20 & 25 & Luging accident & 3 & No & $\begin{array}{l}\text { Headless screw } \\
\text { double Hook Plate }\end{array}$ & Volar rim & No \\
\hline 16 & 62 & 27 & Car accident & 5 & no & $\begin{array}{l}\text { Dorsal plate, } \\
\text { Hook Plate }\end{array}$ & Volar rim & No \\
\hline 17 & 24 & 32 & Fall while skiing & 2 & Volar & $\begin{array}{l}\text { Headless screw, } \\
\text { double Hook Plate }\end{array}$ & Volar rim & Yes \\
\hline 18 & 46 & 31 & Fall from above & 5 & No & $\begin{array}{l}\text { Dorsal plate, } \\
\text { double Hook Plate }\end{array}$ & Volar rim & No \\
\hline 19 & 75 & 10 & Fall while skiing & 1 & No & $\begin{array}{l}\text { Headless screw, } \\
\text { Hook Plate }\end{array}$ & Volar rim & No \\
\hline 20 & 74 & 22 & Patient tripped & 2 & No & $\begin{array}{l}\text { Headless screw, } \\
\text { double Hook Plate }\end{array}$ & Volar rim & No \\
\hline 21 & 27 & 29 & $\begin{array}{l}\text { Motorcycle } \\
\text { accident }\end{array}$ & 3 & No & $\begin{array}{l}\text { Headless screw, } \\
\text { Hook Plate }\end{array}$ & Volar rim & no \\
\hline 22 & 23 & 13 & $\begin{array}{l}\text { Motorcycle } \\
\text { accident }\end{array}$ & 4 & No & $\begin{array}{l}\text { Dorsal plate, } \\
\text { Hook Plate }\end{array}$ & Volar rim & No \\
\hline 23 & 44 & 31 & Fall while skiing & 5 & Dorsal & $\begin{array}{l}\text { Dorsal plate, } \\
\text { Hook Plate, } \\
\text { volar plate }\end{array}$ & Volar rim & No \\
\hline
\end{tabular}




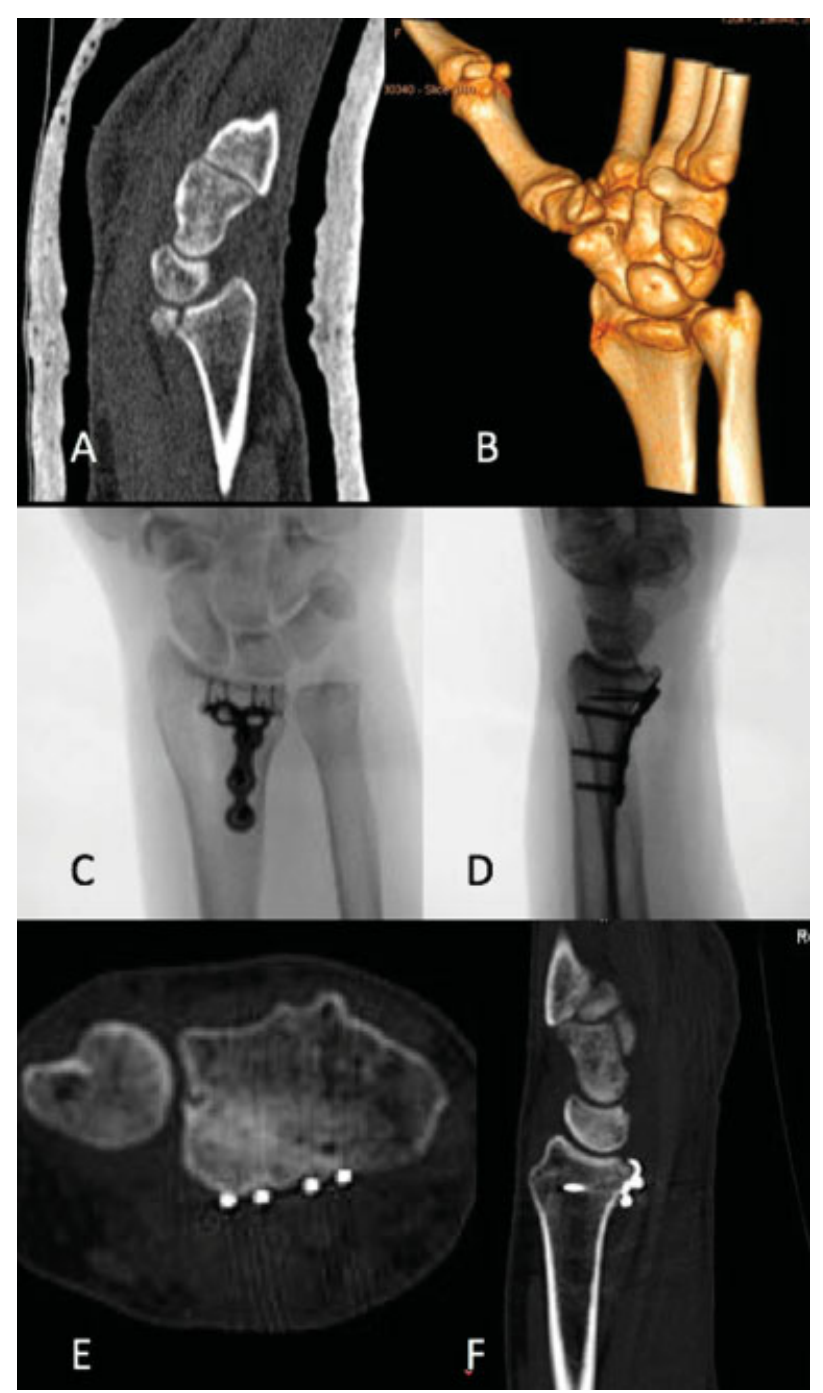

Fig. 2 (A-D) Volar subluxation of the carpus for impacted lunate fossa. The fragment was fixed with one double Hook Plate plus volar plate to buttress and secure the device. (E, F) Postoperative computed tomography scan after 12 months follow-up.

instability. The involvement of this fragment is not so rare $^{12}$ and many studies of the literature have been focused on its treatment. Moreover, the dorsal ulnar corner fragment serves as an attachment site for the dorsal distal radioulnar ligament, whereas the dorsal wall fragment provides stability against dorsal subluxation of the carpus and is an attachment site for the dorsal radiocarpal ligament. The radial column consists of the radial styloid and the scaphoid fossa, which is an attachment site for the brachioradialis tendon, radioscaphocapitate, and long radiolunate ligaments. The intra-articular fragment is often comminuted and impacted into the metaphysis.

Many fixation techniques have been described to treat marginal articular fractures. ${ }^{13,14}$ Over the past decade, reduction and fixation of the "key fragments" was performed with sutures, Kirschner (K)-wires and compression screws. ${ }^{15,16}$ However, these devices are not to suitable to fix small fragments, with a high rate of comminution and fragmentation, loss of reduction, hardware failure, and postoperative radiocarpal instability.

In the last decade, the use of locking plate fixation has shown limited success to address surgical fixation of key fragments. ${ }^{17}$ Their stabilization requires the placement of the plate distal to the watershed line with an increased risk of articular impingement, intra-articular distal screw placement, and late flexor tendons rupture. ${ }^{18}$ Furthermore, anatomical studies have shown the inability of the locking plates to anatomically buttress and stabilize the volar rim. ${ }^{8}$

Since the 1990s, fragment-specific fixation has been successfully utilized. ${ }^{19,20}$ Several devices have been developed until now, but many of them need a previously reduction with K-wires and drilling of the fragments. These procedures are not suitable for small or comminuted fragments and in case of dorsal comminution due to a lack of structural support that allow a dorsal migration of the volar fragments. On the contrary, these devices stabilize only the bone and not the capsule-ligamentous interface in which stabilization is the main goal of the surgical treatment in a picture of radiocarpal dislocation.

The Hook Plate (Aptus Wrist) stabilizes distal fragments at their bone-ligament interface and does not require predrilling. Thus, reduction and stabilization of comminuted or small fragments, distal to the watershed line, is possible even in cases with absence of dorsal structural support. In addition to the bony reduction, the device permits to stabilize the capsule and ligaments in cases of volar bony ligament avulsions due to a dorsal radiocarpal dislocations. The proximal fixation of the device with selfdrilling and self-tapping screws permits to do not penetrate the articular surface, although this procedure must be performed carefully.

The Hook Plate can be applied with a low-profile approach, opening only the distal part of the pronator quadratus, or even in a mini-invasive surgery if combined with cannulated headless screw fixation for a radial styloid fracture. On the contrary, the device showed none interference with a standard volar locking plate fixation, adding a secure fixation of the volar rim.

In our cases, the Hook Plate was able to stabilize impacted or avulsed fragments of the volar rim. Particularly, in cases with dorsal dislocation of the carpus, like in "motorcycle break injuries," the Hook Plate was able to stabilize the volar capsule-ligamentous avulsion and maintain reduction of the radiocarpal joint until bony union. Radiographic outcomes were satisfactory with maintenance of alignment and fixation in all patients. Postoperative CT scans confirmed these data in 12 patients. Complications were not registered, none of the patients required hardware removal. In 16 patients, the Hook Plate was the only device applied on the volar surface of the radius, but no cases of hardware failure were observed despite an early postoperative rehabilitation.

The limitations of the study include a relatively small case series, a short follow-up period, and the presence of heterogeneous fracture subtypes limiting the possibilities to draw definitive conclusions. 


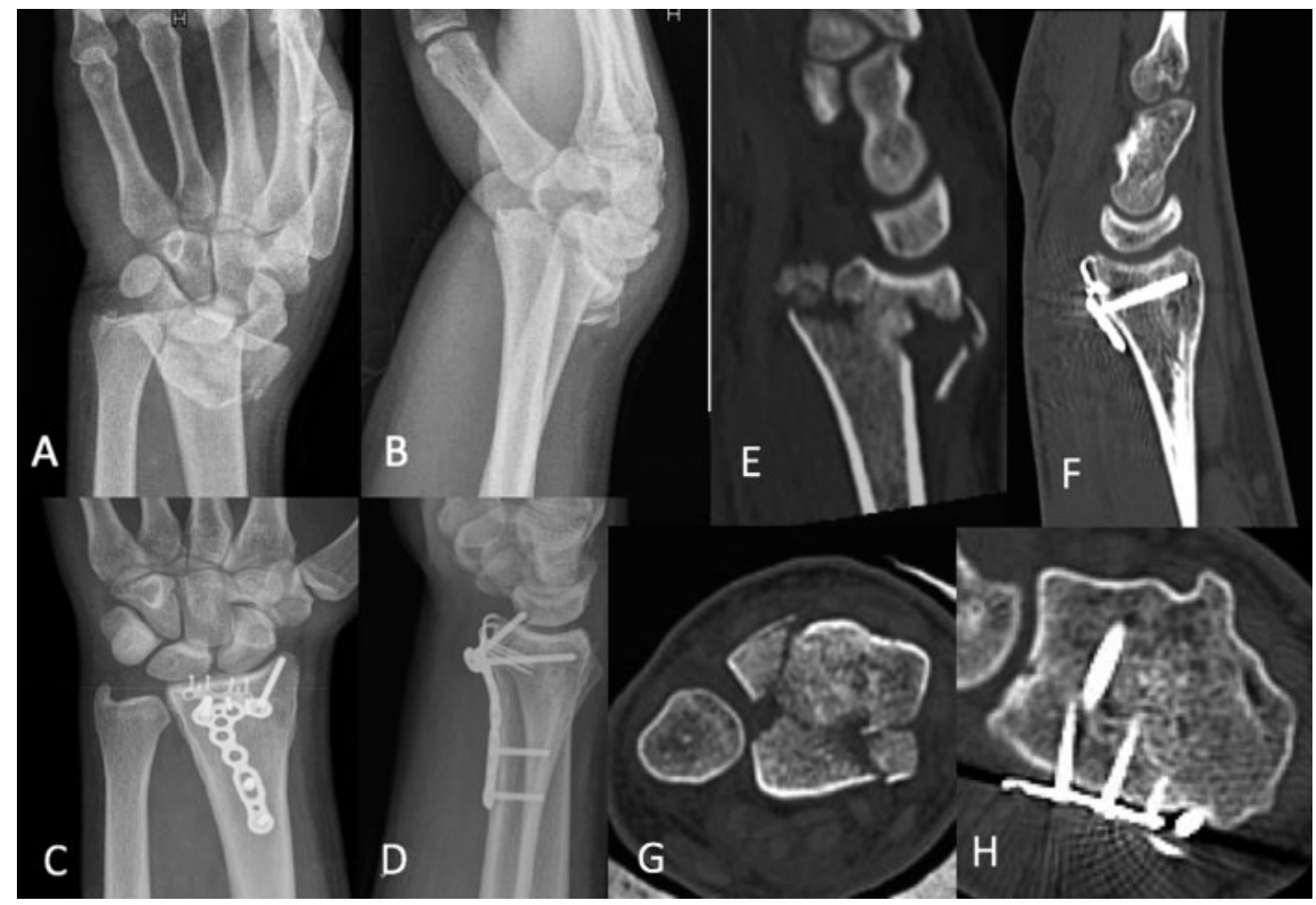

Fig. 3 (A-D) Preoperative and postoperative X-ray control of a four-fragment articular fracture of the distal radius. (E-H) Comparative preoperative and 1-year postoperative follow-up computed tomography scan.

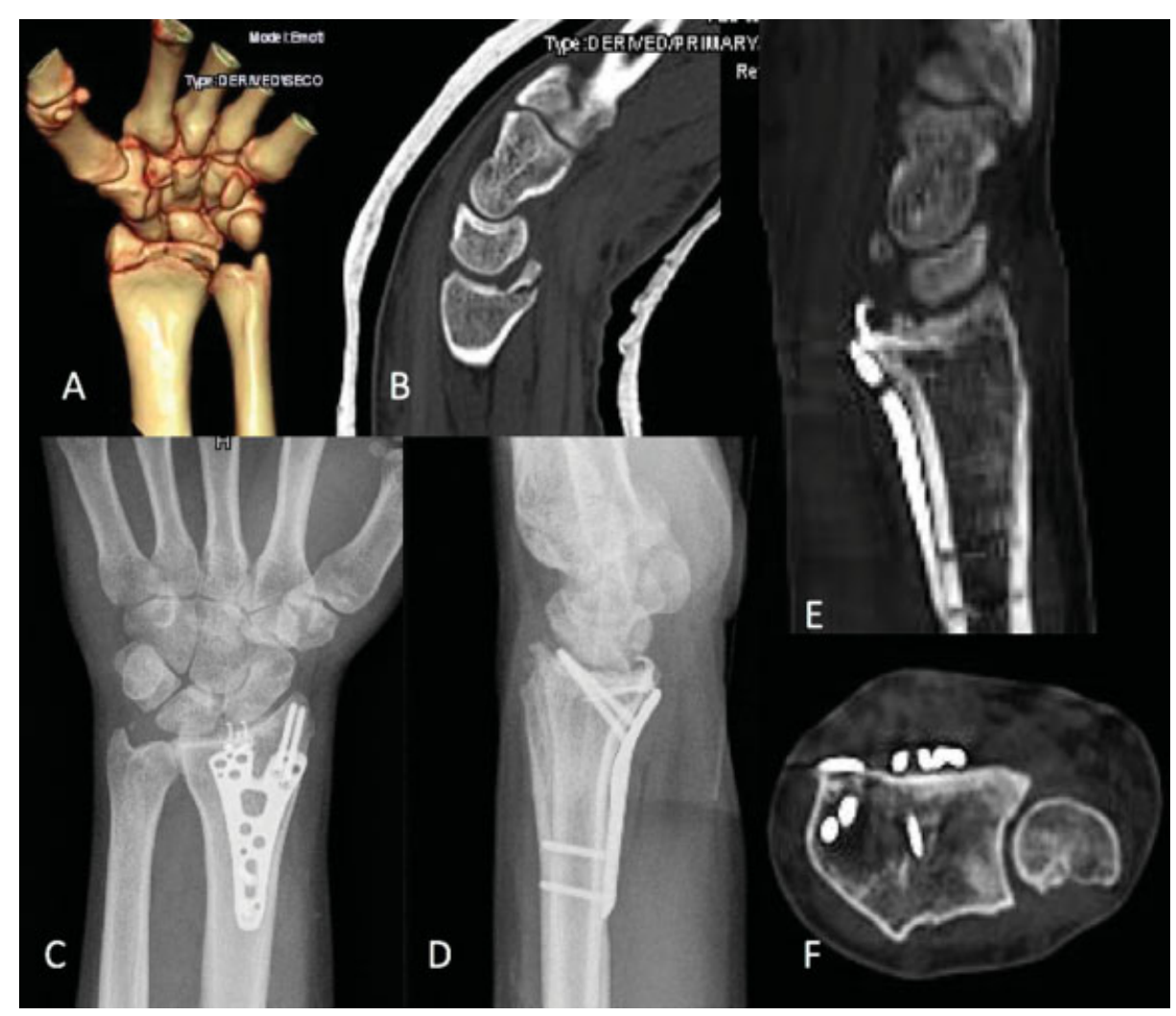

Fig. 4 (A-D) A three-fragment articular fracture of the distal radius. (E, F) The computed tomography scan showed the whole reabsorption of the volar fragment stabilized with the Hook Plate at the last 13th month follow-up. However, the device did not show any signs of loosening or failure, and the carpus remained aligned with the distal radius. 


\section{Note}

This study was conducted in 12 patients at the Hand Surgery Unit, Azienda Ospedaliero Universitaria Careggi (Florence, Italy) and in 11 patients at the Hand Surgery Unit of the Traumatology Department, Medical University (Innsbruck, Austria). Ethical Committee statement was approved on February 16, 2017.

\section{Conflict of Interest}

None declared.

\section{References}

1 Harness NG, Jupiter JB, Orbay JL, Raskin KB, Fernandez DL. Loss of fixation of the volar lunate facet fragment in fractures of the distal part of the radius. J Bone Joint Surg Am 2004;86-A(09):1900-1908

2 Jupiter JB, Fernandez DL, Toh CL, Fellman T, Ring D. Operative treatment of volar intra-articular fractures of the distal end of the radius. J Bone Joint Surg Am 1996;78(12):1817-1828

3 Mall NA, Rubin DA, Brophy RH, Goldfarb CA. Cartilage defect of lunate facet of distal radius after fracture treated with osteochondral autograft from knee. Am J Orthop 2013;42(07):331-334

4 Medoff RJ. Essential radiographic evaluation for distal radius fractures. Hand Clin 2005;21(03):279-288

5 Medoff RJ, Kopilov P. Open reduction and immediate motion of intra-articular distalradius fractures with fragment specific system. Arch Am Acad Orthopedic Surg 1999;2:53

6 Melone CP Jr. Articular fractures of the distal radius. Orthop Clin North Am 1984;15(02):217-236

7 Mandziak DG, Watts AC, Bain GI. Ligament contribution to patterns of articular fractures of the distal radius. J Hand Surg Am 2011;36 (10):1621-1625

8 Andermahr J, Lozano-Calderon S, Trafton T, Crisco JJ, Ring D. The volar extension of the lunate facet of the distal radius: a quantitative anatomic study. J Hand Surg Am 2006;31(06):892-895
9 Marcano A, Taormina DP, Karia R, Paksima N, Posner M, Egol KA. Displaced intra-articular fractures involving the volar rim of the distal radius. J Hand Surg Am 2015;40(01):42-48

10 Ruch DS, Wray WH III, Papadonikolakis A, Richard MJ, Leversedge FJ, Goldner RD. Corrective osteotomy for isolated malunion of the palmar lunate facet in distal radius fractures. J Hand Surg Am 2010;35(11):1779-1786

11 Apergis E, Darmanis S, Theodoratos G, Maris J. Beware of the ulno-palmar distal radial fragment. J Hand Surg [Br] 2002;27 (02):139-145

12 Souer JS, Ring D, Jupiter JB, Matschke S, Audige L, Marent-Huber M; AOCID Prospective ORIF Distal Radius Study Group. Comparison of AO Type-B and Type-C volar shearing fractures of the distal part of the radius. J Bone Joint Surg Am 2009;91(11):2605-2611

13 Moore AM, Dennison DG. Distal radius fractures and the volar lunate facet fragment: Kirschner wire fixation in addition to volar-locked plating. Hand (NY) 2014;9(02):230-236

14 Chin KR, Jupiter JB. Wire-loop fixation of volar displaced osteochondral fractures of the distal radius. J Hand Surg Am 1999;24 (03):525-533

15 Halbrecht JL, Stuchin SA. Unusual fragment displacement in a distal radius fracture. J Hand Surg Am 1988;13(05):746-749

16 Takami H, Takahashi S, Ando M. Comminuted intra-articular fracture of the distal radius with rotation of the palmar medial articular fragment: case reports. J Trauma 1992;32(03):404-407

17 Beck JD, Harness NG, Spencer HT. Volar plate fixation failure for volar shearing distal radius fractures with small lunate facet fragments. J Hand Surg Am 2014;39(04):670-678

18 Soong M, Earp BE, Bishop G, Leung A, Blazar P. Volar locking plate implant prominence and flexor tendon rupture. J Bone Joint Surg Am 2011;93(04):328-335

19 Benson LS, Minihane KP, Stern LD, Eller E, Seshadri R. The outcome of intra-articular distal radius fractures treated with fragmentspecific fixation. J Hand Surg Am 2006;31(08):1333-1339

20 Geissler WB, Fernandez DL. Percutaneous and limited open reduction of the articular surface of the distal radius. J Orthop Trauma 1991;5(03):255-264 